\title{
The Toxicological Studies of Securidaca longepedunculata on the Heart, Liver, Kidney and Lungs of Rats
}

\author{
Haruna $Y^{*}$ \\ Department of Medicinal Chemistry, Kebbi State University of Science and \\ Technology, Nigeria \\ *Corresponding author: Haruna Y, Department of Medicinal Chemistry, Kebbi State \\ University of Science and Technology, P.M.B. 1144, Aliero, Birnin Kebbi, Nigeria, \\ Email: yusufsomko@gmail.co
}

\begin{tabular}{|c|}
\hline Research Article \\
Volume 4 Issue 2 \\
Received Date: March 07, 2019 \\
Published Date: April 16, 2019 \\
DoI: $10.23880 /$ act-16000153 \\
\hline
\end{tabular}

\begin{abstract}
Securidaca lonpedunculata is a savannah plant widely distributed in Africa. The plant has a reputation of broad spectrum of medicinal, pharmacological and therapeutic properties, it is reported that almost all parts of the plant are used by man for different ailments. Our investigation examined the histopathologic effects of the methanol root extract of $S$. longepedunculata on the kidney, liver, lungs and the heart. Wister albino rats weighing 170 to $200 \mathrm{~g}$ were given 0.56, 0.28 , and $0.14 \mathrm{mg} / \mathrm{kg}$ (i.p.) respectively of the extract daily for 60 days and then sacrificed. The methanol extract gave an $\mathrm{LD}_{50}$ value of $2.8 \mathrm{mg} / \mathrm{kg}$ (i.p.) and histological examinations revealed that in the kidneys, there was intense vascular congestion with kupfer cells hyperplasia, similar changes were observed in the liver showing slight hepatic necrosis and lymphocyte hyperplasia. The histological changes resemble those produced by chronic ethanol and paracetamol ingestion suggesting the presence of toxic constituents. Hence, the use of $S$. longepedunculata may be associated with tissue structural damage of some vital organs.
\end{abstract}

Keywords: Extract; Histopathology; Kidney; Liver; Securidaca Lonpedunculata; Wister Albino Rats

\section{Introduction}

S. longepedunculata is a shrub or a small $2-10 \mathrm{~m}$ high flowering savannah tree which is widely distributed in tropical Africa and occurs naturally in the north-western and western part of Nigeria and Northern Province of South Africa [1]. It is known to possess a broad spectrum of medicinal, pharmacological and therapeutic properties. It is reported that almost all parts of the plant (leaves, twigs, stem bark, roots and seeds) are used by man for different purposes such as medicine, source of fibre, water purifying agents, an ornament, fish poison, molluscicides, snake repellent or as an insect repellent [2].
In many parts of Africa the plant is employed in traditional medicine principally for its psychotropic properties; aqueous extracts of this root are used as psychopharmacological agents [3]. Ergot alkaloids have also been confirmed by the same authors in the extracts. The roots of the plant are very poisonous and are said to contain methyl salicylate. In some parts of Africa they are used as arrow poison [4]. Despite the varied uses of this in treating a plethora of human and animal ailments, its toxicological profile has not been reported to our knowledge $[5,6]$. 
When a herbal product is ingested the body interacts with it in an attempt to remove any harmful toxins, especially if the body cannot convert the foreign substances into cellular components. The challenges are commonly manifested by changes in enzyme levels and other cell components. The enzymes commonly involved include: aspartate aminotransferase (AST), alanine aminotransferase (ALT), creatinine kinase (CK) amylase and alkaline phosphate. Urea and uric acid are also vital diagonistic tools for toxicity. It was found that aqueous extracts of the root bark of $S$. longepedunculata altered serum levels of these enzymes in rats [7]; an indication of the potential toxicity of the plant which could result in organ or tissue damage. The vital organs that are commonly affected are heart, liver, kidney and pancreas among others. The aim of this study is to investigate the effect of the plant roots on tissue histology as a marker of toxicity.

\section{Materials and Methods}

\section{Plant Material}

Roots were harvested from Securidaca longepedunculata plants collected from Zuru, in Kebbi State, North-Western Nigeria. The identity of the whole plant was confirmed by Mr U.S. Gallah, a taxonomist of the Herbarium Section of Department of Biological Sciences, Ahmadu Bello University Zaria, Nigeria; where a voucher specimen was deposited for future reference purposes and assigned a voucher number: 900149.

\section{Experimental Animals and Animal Husbandry}

Wister albino rats (170-200 g) of both sexes used for this study were purchased from the Animal House of the Department of Pharmacology and Therapeutics, Ahmadu Bello University, Zaria, Nigeria. Metallic and plastic cages constructed in Samaru, Zaria were used to house the animals. The animals were clinically examined and confirmed to be free of trypanosomes and plasmodia organisms. They were fed with standard rodent feed (Vital Feeds, Jos, Nigeria), and allowed access to tap water ad libitum. Individual animals were coded using picric acid [8].

\section{Acute Toxicity Evaluation / Determination of Median Lethal Dose LD 50 (I.P. Route)}

The method of Lorke (1983) was used for the $\mathrm{LD}_{50}$ determination. Three animals were given widely differing doses for each of the test groups in phase one as; 10 $\mathrm{mg} / \mathrm{kg}, 100 \mathrm{mg} / \mathrm{kg}, 1000 \mathrm{mg} / \mathrm{kg}$ respectively and a control group was given normal saline according to the weight of the animal. The animals were observed for toxic signs, and for further 24 hours, the number(s) of death(s) were recorded. The doses of second phase were selected based on the outcome of the first phase and observed further closely for yet another 24 hours too. The number(s) of death(s) or none in the groups were used to calculate the $\mathrm{LD}_{50}$ as [6].

$\mathrm{LD}_{50}=\sqrt{ }$ The Maximum Dose of Survival $\mathrm{X} \sqrt{ }$ The Minimum Dose that caused death

\section{Sub-chronic Toxicity Studies on the Methanolic Extract}

The method described by Cha, et al and adopted by Adeyemi was used for these studies. In these studies, rats were treated with methanol extract throughout. Ninety six male adult Wister rats were randomized into four groups each containing 24 rats and the following protocol was adopted. The rats were allowed to acclimatize to laboratory conditions for two weeks before the commencement of the study. Tween $80(0.3 \% \mathrm{v} / \mathrm{v})(0.2$ $\mathrm{ml} / \mathrm{kg}$ ) was used as vehicle for administration of $S$. longepedunculata $[9,10]$.

Group 1: No treatment with extract

Group 2: $0.14 \mathrm{mg} / \mathrm{kg}$ of Securidaca longepedunculata extract (SLE)

Group 3: $0.28 \mathrm{mg} / \mathrm{kg}$ of SLE

Group 4: $0.56 \mathrm{mg} / \mathrm{kg}$ of SLE.

Administration of the extract stopped after 60 days and the intention was to monitor surviving rats for 90 days. The rats were observed daily for clinical signs and symptoms of toxicity as well as weekly body weight changes. Six rats from each group were sacrificed at the end of weeks 2, 4 and 8; after which the experiment was terminated because the rats did not survive the 90 days. The kidneys, liver, lungs and heart were excised for light microscopic studies. Sections of each tissue were immersed immediately into $250 \mathrm{ml}$ of neutralized $10 \%$ (v/v) formalin. The tissues were kept in the fixative for 12 hours, dehydrated with serial ethanol cycles $(70 \%$ to absolute) and then embedded in paraffin. The paraffin embedded tissue was cut into $5 \mu \mathrm{m}$ sections. The tissue sections were de paraffinised and stained with Mayer hematoxylin and eosin stains for light microscopic analysis.

\section{Statistical Analysis}

Results were presented as mean \pm SEM. Tests of significance between means were done using Student t- 


\section{Advances in Clinical Toxicology}

test and ANOVA as appropriate. Level of significance would be considered to be $\mathrm{P}<0.05$.

\section{Results}

In our study, administration of $S$. longepedunculata to rats produced dose dependent multiple organ toxicities in the kidney and the liver. Estimation of $\mathrm{LD}_{50}$ gave a value of $2.83 \mathrm{mg} / \mathrm{kg}$ in rats (Tables 1 and 2). Animals administered with the extract showed signs of respiratory distress (gasping) and muscles paralysis with a stretching of the hind limbs at the points of death.

\begin{tabular}{|c|c|c|c|}
\hline Group & Dose (mg/kg) & No. Used & No. of Deaths \\
\hline Normal Saline & - & 3 & 0 \\
\hline 1 & 10 & 3 & 2 \\
\hline 2 & 100 & 3 & 3 \\
\hline 3 & 1,000 & 3 & 3 \\
\hline
\end{tabular}

Table 1: Phase I of $\mathrm{LD}_{50}$ (Intra-Peritoneal) of $S$. longepedunculata on mice.

\begin{tabular}{|c|c|c|c|}
\hline Group & Dose (mg/kg) & No. Used & No. of Deaths \\
\hline 1 & 2 & 1 & 0 \\
\hline 2 & 4 & 1 & 1 \\
\hline 3 & 8 & 1 & 1 \\
\hline 4 & 16 & 1 & 1 \\
\hline
\end{tabular}

$\mathrm{LD}_{50}=2.8 \mathrm{mg} / \mathrm{kg}$

Table 2: Phase II of $\mathrm{LD}_{50}$ (Intra-Peritoneal) of $S$. longepedunculata on mice

\section{Effect of the Extract on Tissue Morphology}

In the kidneys, the histopathologic changes were that of vascular congestion with intense lymphocyte hyperplasia with kupfer cells. This suggests that cellular injury affecting the epithelial parenchyma and endothelial cells occurred (Figure 1). Similar changes were observed in the liver in which there was slight hepatic necrosis, lymphatic hyperplasia and hepatic congestion and kupfer cells hyperplasia in the liver cells (plates 2 and 4) However, no pathological changes were observed in the heart at the three respective doses.

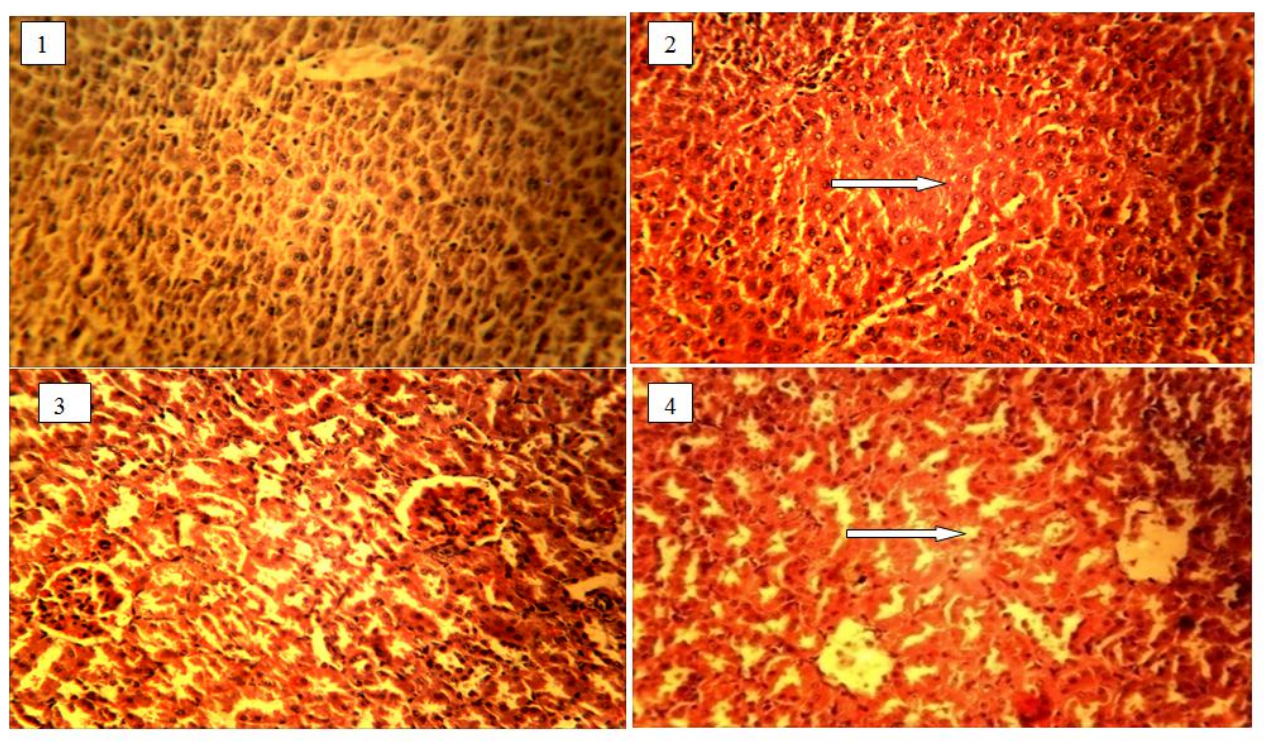

Figure 1: Histology of the liver of rats (1\&2) showing the control and the one administered with $(0.56 \mathrm{mg} / \mathrm{kg})$ extracts of $S$. longepeduncuata.

1. Normal liver No lesions

2. Slight hepatic necrosis, lymphocyte hyperplasia

3. Normal kidney

4. Intense vascular congestion with kupfer cells hyperplasia
Histology of the kidney of rats (3\&4) showing the control and the one administered with $(0.56 \mathrm{mg} / \mathrm{kg})$ extracts of $S$. longepedunculata. 


\section{Discussion}

S. longepedunculata is known to possess a broad spectrum of medicinal, pharmacological and therapeutic properties. It is reported that almost all parts of the plant (leaves, twigs, stem bark, roots and seeds) are used by man for different purposes such as medicine, source of fibre, water purifying agents, an ornament, fish poison, molluscicides, snake repellent or as an insect repellent [2]. Yet available literature revealed no published report on its toxicity. In our study, intra-peritoneal administration of the root extract of $S$. longepedunculata in rats produced dose dependent multiple organ toxicities; the kidney and the liver but not noticed in the heart in the three respective doses. Estimation of the $\mathrm{LD}_{50}$ gave a value of $2.83 \mathrm{mg} / \mathrm{kg}$ in rats. This is of immense importance, in view of the large-scale human consumption of this plant, and should be a matter of concern, even though $\mathrm{LD}_{50}$ is not a very reliable procedure in the determination of toxicity as there is a wide variation in results between different species and even in the same species under different experimental conditions. Moreover, $\mathrm{LD}_{50}$ provides no information on what system failure led to the death of the animals. However, the $\mathrm{LD}_{50}$ in conjunction with photomicrographs of stained tissues gave a good picture of the toxic characteristics of the plant. Kidney and liver histology of treated rats showed features consistent with renal and liver injuries from toxins. Many herbal preparations have been found to exhibit renal tubular necrosis showing extensive interstitial fibrosis and severe tubular loss most prominent in the outer cortex. Some histological results showed that aristolochic acid was nephrotoxic in female Wister rats which rapidly developed renal tubular necrosis and renal failure $[5,9,10]$. The significance of this in traditional practice needs to be evaluated especially because the plant has been found to exert hypoglycaemic properties, and some herbalists promote its use in diabetes mellitus; a syndrome that is almost always associated with nephropathy [11].

Extracts of $S$. longepedunculata significantly increased levels of serum AST and ALT [7]. This is diagonistic of hepatocellular damage, as seen in the disorders that cause the death of many numerous liver cells (extensive hepatic necrosis) such as acute viral hepatitis A or B, pronounced liver damage inflicted by toxins as from an over dose of acetaminophen (paracetamol), and prolonged collapse of the circulatory system (shock) when the liver is deprived of fresh blood bringing oxygen and nutrients [12]. Histological findings in this study are characterized by focal hepatocellular necrosis similar to the pattern of damage induced by paracetamol. Effect of the extract on the pulmonary, brain and spleen does not indicate any specific pattern of toxicity; the damage to alveoli and bronchiolar epithelium could have been a result of direct toxicity or could have resulted in transportation of toxic substances from other organs like the liver and kidneys to the lungs. All the more, respiratory toxicity of the plant is apparent even if the mechanism of this is not clear. Rats treated were observed to be in severe respiratory distress prior to death. These changes are similar to those found in acute or chronic ethanol-induced cell injury [13].

\section{Conclusion}

This study has demonstrated the tissue toxicity of $S$. longepedunculata in rats. Patients usually combine herbal remedies with orthodox medication or with alcohol often without the knowledge of the pharmacist or the physician. Considering the potential toxicity of $S$. longepedunculata herbal practitioners should be educated on this especially when this plant is recommended as part of the complex regimen in the long term or short term management of chronic illnesses like hypertension and diabetes. Further study is recommended in order to isolate the specific component(s) of the plant responsible for the toxicity in order to standardise the plant preparation for maximum therapeutic benefit.

\section{References}

1. Ojewole JO, Ilesanmi ORS, Olayiwola G (2000) Pharmacology of African Medicinal Plants. Neuromuscular and Cardiovascular Properties of $S$. longepedunculata Nigerian. J of Nat Prod Medicine 4.

2. Neuwinger HD (1996) African ethno-botany poisons and drugs, chemistry, pharmacology, toxicology. Pharmaceutical Biology. Chapman \& Hall, London. UK, pp: 743-753.

3. Winkelman M, Dolbkin R (1989) Psychactive Properties of Kung Bushmen Medicinal Plants. J Psychactive Drugs 21(1): 51-59.

4. Sapeika N (1944) Fatal human poisoning from plants in Southern Africa. Clinical Proceedings 3: 64-91.

5. Dapar LPM, Aguiyi CJ, Wannang NN, Gyang SS, Tanko MN (2007) The histopathologic effects of Securidaca longepedunculata on heart, liver, kidney and lungs of rats. African Journal of Biotechnology 6(5): 591-595.

6. Lorke D (1983) A new approach to practical acute toxicity. Achieves of toxicology 54(4): 275-287. 


\section{Advances in Clinical Toxicology}

7. Wannang NN, Wudil AM, Dapar LMP, Bichi LA (2005) Evaluation of anti-snake venom activity of the Aqueous root extract of Securidacalonge pendunculata in rats. J Pham Bio Res 2(2): 80-83.

8. Adeyemi IA (1988) Ogi quality of sorghum flour drymilled from fermented sorghum grains. Journal of food science 53(2): 641-642.

9. Cha J, Elsebet ON, Jang HO, Tage H, John BP, et al. (1988) Thiocyanate Stabilizes AMPA binding to the quisqualatereceptor. European Journal of Pharmacology 157(2-3): 197-203.
10. Mengs U, Lang W, Poch JA (1982) The Carcinogenic Action of Aristolochic Acid in Rats. Arch Toxicol 51(2): 107-119.

11. Weghem R, Gazzad B, Peto R (1993) WHO Drug Information $7(2)$.

12. Kolawole JA, Onyeche OC (2005) Preliminary Screening of Aqueous Extract of the Leaves of Securidaca longepedunculata for Anti-hyperglycaemic Property; Nig. J of Pharm Res 4(2): 18-21.

13. McCain CJ, Cohen DA (1989) Increased tumour necrosis factor production by monocytes in alcoholic disease. Hepatology 9(3): 349-351. 